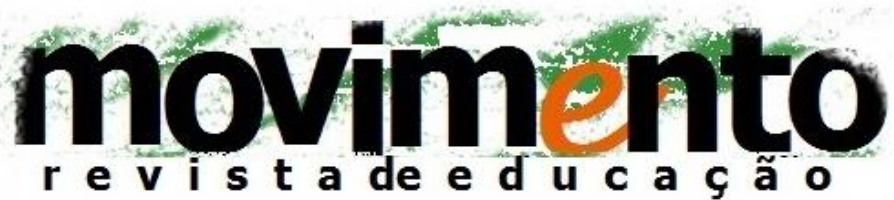

faculdade de educação - programa de pós-graduação em educação

universidade federal fluminense

issn 2359-3296

ano 3 número 5 - 2016

\section{ATUAÇÃO DOS GOVERNOS ESTADUAIS NA EFETIVAÇÃO DO ACESSO À EDUCAÇÃO INFANTIL: tema para o debate ${ }^{1}$}

\author{
Luciane Muniz R. Barbosa \\ Theresa Adrião²
}

\section{RESUMO}

O presente artigo tem como objetivo refletir sobre o direito à Educação Infantil no Brasil, de modo a indagar sobre a participação dos governos estaduais na garantia desse direito, considerado um dever do Estado cuja viabilização depende do efetivo exercício de colaboração entre os entes federados. Neste caso, opta-se por analisar informações sobre o conjunto dos estados brasileiros, como: as performances das matrículas estaduais nesta etapa; os PIBs dos respectivos estados e os partidos políticos das gestões governamentais iniciadas a partir da vigência da Lei de Responsabilidade Fiscal. Ressalta-se a necessidade de revisão do pacto federativo no âmbito de formas de cooperação para a oferta da Educação Infantil no país, também como forma de combate à privatização e precarização do atendimento educacional das crianças pequenas.

Palavras-chave: Educação Infantil; governos estaduais; cooperação federativa; partidos políticos

\section{ABSTRACT}

The purpose of the this paper is to reflect upon the right to Early Childhood Education in Brazil, in such a way as inquire the role of local state governments in safeguarding such right, one that is deemed to be a State responsibility and whose accomplishment depends on the actual collaboration among the federated states. In the present case, we have decided to analyze information on the Brazilian federated states as a whole, such

\footnotetext{
${ }^{1}$ Parte deste texto foi apresentada no V Congresso Ibero-Americano de Política e Administração da Educação e VIII Congresso Luso-Brasileiro de Política e Administração da Educação, em Goiânia, em 2016. Tratam-se de resultados iniciais da pesquisa "Análise das políticas estaduais de apoio aos municípios para o atendimento da Educação Infantil no Brasil (2005-2015), coordenada por Luciane Barbosa, desenvolvida no âmbito do Grupo de Estudos e Pesquisa em Política Educacional (GREPPE) e resultante de dados inventariados na realização da pesquisa MAPEAMENTO DAS ESTRATÉGIAS DE PRIVATIZAÇÃO DA EDUCAÇÃO BÁSICA NO BRASIL (2005-2015), coordenada por Theresa Adrião.

${ }^{2}$ Professoras na Faculdade de Educação da Universidade Estadual de Campinas/Unicamp.
} 


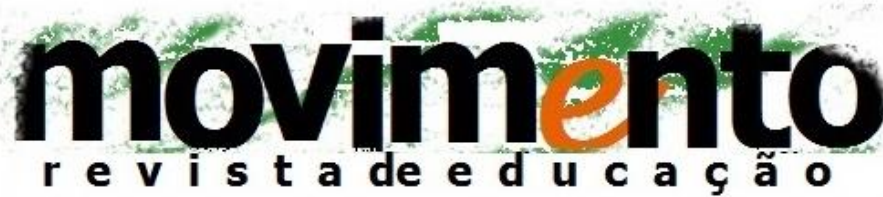

faculdade de educação - programa de pós-graduação em educação

universidade federal fluminense issn 2359-3296

ano 3 número 5 - 2016

as the number of actual enrollments in this stage of education, the states' GDP, and the political parties ahead of the government administrations as from the enactment of the Fiscal Responsibility Law. We emphasize the need for a revision of the federal agreement as regards the cooperation mechanisms relating to the offer of Early Childhood Education in the country, also as way to oppose the privatization and debilitation of the educational services provided to young children.

Key-words: Early childhood education; state governments; federalist cooperation; political parties

\section{Introdução}

Avalia-se como um avanço a expansão do direito à Educação Infantil (EI) no Brasil, considerado um dever do Estado e um direito de todas as crianças de 0 a 5 anos, após a Constituição Federal de 1988 (CF/88) e a Lei de Diretrizes e Bases da Educação (LDB) 9394/96. Apesar das conquistas legais, que resultaram na expansão das vagas e da taxa de frequência das crianças pequenas na Educação Infantil, ainda há muito a ser realizado, pois, o déficit do atendimento à demanda real e potencial para essa etapa da educação se revela significativo.

Nesse contexto, destaca-se o modelo de financiamento desta etapa da Educação Básica que, tendo o município como ente federado prioritariamente responsável pelo seu financiamento e diante do Fundo de Manutenção e Desenvolvimento da Educação Básica e de Valorização dos Profissionais da Educação (Fundeb - Emenda Constitucional no 53/2006), acaba por induzir uma série de iniciativas de levam à privatização e precarização do atendimento educacional das crianças pequenas. Essa condição induz os governos municipais a desenvolverem iniciativas privatizantes para ampliar o acesso a essa etapa da educação, sobretudo como cumprimento da Meta 1 estabelecida 


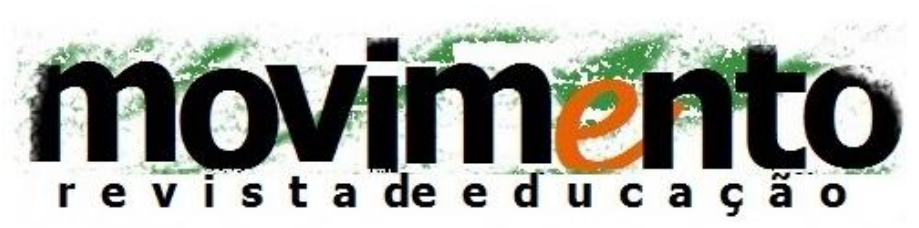

faculdade de educação - programa de pós-graduação em educação

universidade federal fluminense issn 2359-3296

ano 3 número 5 - 2016

pelo atual Plano Nacional de Educação (PNE) (Lei 13.005/2014) que prevê a universalização da Educação Infantil na pré-escola para as crianças de 4 a 5 anos de idade (até 2016) e a ampliação da oferta em creches de forma a atender, no mínimo, 50\% das crianças de até 3 anos até 2024 .

A questão central presente nessa reflexão é que, apesar da oferta da El ser prioritariamente responsabilidade dos municípios, não significa que a responsabilidade pela garantia de sua oferta ela deva ser exclusiva deste, já que, segundo a lei, os entes federados deverão organizar em regime de colaboração os respectivos sistemas de ensino (CF/88, Art. 211; LDB 9394/96, Art. 8), sendo que: "Na organização de seus sistemas de ensino, a União, os Estados, o Distrito Federal e os Municípios definirão formas de colaboração, de modo a assegurar a universalização do ensino obrigatório" (Art. $211, \S 4^{\circ}$ ), no qual encontra-se a pré-escola.

Oliveira e Ganzeli (2013, p. 1033) ressaltam a importância da previsão constitucional do regime de colaboração, contudo, destacam a necessidade de compreensão do fato de que:

[...] são os governos (nacional, regional e local) que produzem a materialização do regime de colaboração, com acertos e desacertos conjunturais e históricos. Nesse sentido, estamos compreendendo essas relações intergovernamentais como políticas de Estado ou políticas de governo.

Assim, quando analisamos o cumprimento do dever estatal quanto à oferta da $\mathrm{El}$, revela-se necessário investigar as formas de colaboração que os entes federados vêm realizando para tal intento. Debruçar-se sobre essa questão 


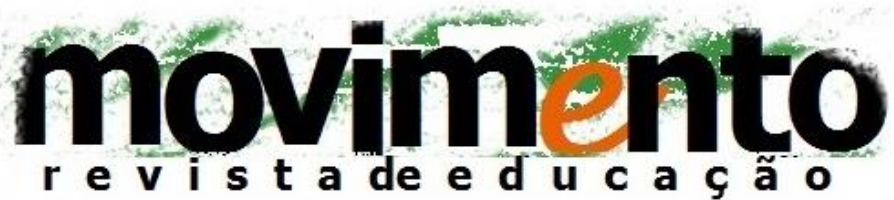

faculdade de educação - programa de pós-graduação em educação

universidade federal fluminense issn 2359-3296

ano 3 número 5 - 2016

significa evidenciar a relevância de se analisar as políticas para a Educação Infantil em um estado federativo, dado que

[...] sua forma de organização político-administrativa, a forma como distribui territorialmente o poder, a forma como estabelece relações com as unidades subnacionais e a forma como distribui poderes e recursos financeiros para essas unidades têm implicações diretas na implantação e implementação das políticas de ampliação do acesso e da permanência na escola, que constituem o direito à educação. (ARAUJO, 2013, p. 37)

Trata-se, neste texto, de apresentar e analisar informações sobre o conjunto dos estados brasileiros que permitam indagar sobre a presença dos governos estaduais na garantia do direito à educação infantil por meio da oferta de vagas. Para tanto, foram analisadas as performances das matrículas estaduais nesta etapa da educação, os valores do Produto Interno Bruto (PIB) dos respectivos estados e os partidos políticos dos governadores em exercício no período de 2005 a 2015. Por performance de matrículas entendem-se as variações, no período selecionado, no montante de matrículas totais em creches e pré-escolas na esfera administrativa estadual.

O período investigado corresponde ao primeiro ano de vigência completa da Lei complementar n. 101 de 2000, chamada lei de Responsabilidade Fiscal (LRF), e o ano de 2015. Nessa análise inicial ${ }^{3}$, para além das matrículas totais na Educação Infantil, buscou-se levar em consideração os partidos que iniciaram as três gestões aqui mencionadas (2003 a 2006, 2007 a 2010 e 2011 a 2014) e o

\footnotetext{
${ }^{3}$ Dados coletados em fontes oficiais, como: INEP, para dados de matrícula; IBGE para dados de PIB per capita; e tribunais regionais eleitorais para partidos políticos (os partidos apresentados são referentes às posses regulares - $1^{\circ}$ de janeiro do ano posterior à eleição - e não consideram eventuais alterações de posse).
} 


\section{$\operatorname{movim}_{\text {revistade educaço }}$}

faculdade de educação - programa de pós-graduação em educação

universidade federal fluminense issn 2359-3296

ano 3 número 5 - 2016

PIB nos anos considerados como o segundo de cada gestão ${ }^{4}$, ano no qual se apresentam os Planos Plurianuais (PPA).

O PPA, previsto no art. 165 da CF/88 e regulamentado pelo Art. $3^{\circ}$ da Lei Complementar 101/2000, apresenta-se como mecanismo complementar de planejamento público, que se inicia no mandato anterior e a partir do qual é vetado aos governos efetuarem despesas não previstas neste documento. As prioridades dos governos são objetos de definição durante o primeiro ano do exercício de cada novo mandato, devendo ser cumpridas no primeiro ano do mandato seguinte quando, até o final de agosto, deve ser enviado ao legislativo novo PPA. É com base no que nele está previsto que os governos elaboram suas Leis de Diretrizes Orçamentárias, para vigorarem nos anos subsequentes e suas Leis Orçamentárias anuais executadas no próprio ano.

Ainda que neste trabalho não se discuta o assinalado pelos governos estaduais para o atendimento à educação infantil nessas peças de planejamento, acreditase que as performances das matrículas auxiliam a captar e ilustrar tais prioridades. $O$ trabalho também tem como objetivo promover indagações, mais que explicitar possíveis relações entre os perfis sócio econômicos dos estados e as opções de atendimento à educação básica visualizadas pela totalização das matrículas na rede estadual, indicando possibilidades para futuras investigações.

\footnotetext{
4 Tendo em vista a série histórica analisada neste artigo (2005 a 2015), os PIBs considerados foram os de 2005 (mesmo não se tratando do segundo ano do governo em vigência, mas de ano em que o PPA já estava em vigor), 2008 e 2012 (dado que os valores de PIB per capita de 2015 não foram divulgados pelo IBGE até a publicação deste trabalho). Os valores de PIB per capita foram corrigidos conforme o Índice Nacional de Preços ao Consumidor (INPC/IBGE), com base no ano de 2015.
} 


\section{movimento \\ faculdade de educação - programa de pós-graduação em educação \\ universidade federal fluminense \\ issn 2359-3296 \\ ano 3 número 5 - 2016}

\section{Sobre o contexto e a Lei de Responsabilidade Fiscal ${ }^{5}$}

As tentativas de reforma na gestão pública brasileira, desenhadas pelo Plano Diretor da Reforma do Aparelho de Estado de 19956, ganharam organicidade e materialidade com a Emenda Constitucional (EC) n. 19 de 1998. Em linhas gerais, as alterações no texto original da Carta Maior, assentam-se em pressupostos e orientações advindas na Nova Gestão Pública.

Dentre as mudanças introduzidas destacam-se a normalização do financiamento público para oferta de serviços e atividades (como educação, saúde e cultura) por instituições não governamentais, a regulamentação das parcerias públicoprivadas e a lei de Responsabilidade Fiscal (ADRIÃO e BEZERRA, 2013).

Esse conjunto de medidas possibilita o estabelecimento, em quase todos os Estados, do modelo de Governança, forma de gestão sugerida por agências internacionais, especialmente pelo Banco Mundial, pautada numa certa revisão das orientações radicalmente liberalizantes do final do século XX e na percepção de que Estado deve atuar como agente indutor do desenvolvimento e da equidade. A governança pressupõe a presença direta de corporações e de setores privados a elas associados na definição e na gestão das políticas.

\footnotetext{
${ }^{5} \mathrm{O}$ impacto da LRF é assunto de interesse de diversas áreas. Recentemente, pesquisa publicada pelo IPEA, verificou que os municípios que gastavam mais de $60 \%$ da Receita Corrente Líquida com pessoal diminuíram seus gastos em relação à receita após a LRF, enquanto parte dos municípios que gastavam abaixo do limite imposto pela Lei aumentaram seus gastos relativos. (MENEZES; TONETO JR., 2006, p. 7 a 38)

${ }^{6}$ Para mais informações, ver PERONI, Vera Maria Vidal. Política educacional e papel do Estado no Brasil dos anos 90.São Paulo: Xamã, 2003.
} 


\section{movimento}

faculdade de educação - programa de pós-graduação em educação

universidade federal fluminense issn 2359-3296

ano 3 número 5 - 2016

É nesse contexto que a Lei 101/2000, LRF, foi instituída. Seu conteúdo, dentre outras ações, delimita os gastos do poder público, fixando em $60 \%$ as despesas com pessoal, trava que induziu o aumento das parcerias entre os municípios e 0 setor privado, estimulando a opção pela terceirização dos serviços especialmente nas áreas de maior presença de contratação, como é o caso da educação ${ }^{7}$ (ADRIÃO et al, 2009).

Soma-se a esse mecanismo a ampliação da obrigatoriedade escolar para 9 anos (6 aos 14) a partir de 2006, por meio da a Lei federal o 11.274 e, posteriormente, para 14 anos (4 aos 17, compreendendo a pré-escola, Ensino Fundamental e Ensino Médio), em decorrência da Lei Federal 12.796/2003. Em resumo, no período analisado, a educação básica brasileira encontra-se premida pela ampliação do atendimento educacional em um contexto de restrição de gasto com pessoal, sabidamente o item de despesa que mais concentra gastos, dado o uso intensivo de funcionários que a natureza das atividades escolares exige.

Um último aspecto agrega-se a este breve enquadramento: trata-se do papel desempenhado pelos governos estaduais na oferta e na manutenção da educação básica. Temos insistido no papel prioritário que a organização da educação no Brasil destina aos municípios (ADRIÃO et al 2009; 2014; 2015), sendo estas esferas que respondem, em última instância, pela garantia do direito à educação às crianças de 0 aos 14 anos de idade. Ainda que o texto constitucional preveja um necessário regime de colaboração para tal feito, é certo que

[...] embora os municípios possuam matrícula na educação básica maior que aquela apresentada pelos estados, sua receita líquida de impostos é bem inferior

\footnotetext{
${ }^{7}$ Segundo o IPEA entre 2004 e 2006, aumentou em 9,8\% a participação de pessoas sem vínculo sobre o total de funcionários na administração direta.
} 


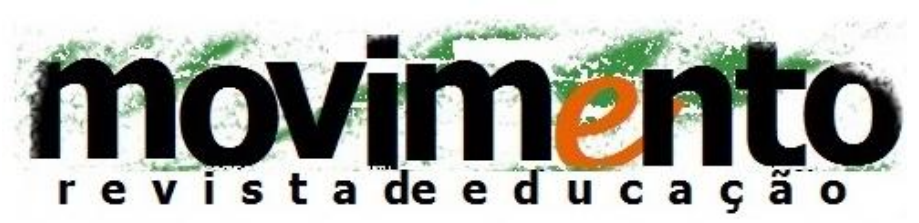

faculdade de educação - programa de pós-graduação em educação

universidade federal fluminense issn 2359-3296

ano 3 número 5 - 2016

àquela obtida pelos estados (cerca de três quartos), o que demonstra uma situação de grande fragilidade do atual sistema de financiamento. (PINTO, 2007 p.10)

Assim, revela-se necessária a reflexão sobre a atuação dos governos dos Estados brasileiros na oferta da Educação Infantil, como primeira etapa da Educação Básica, como propõe este trabalho, de modo a contribuir para a revisão da oferta educacional baseada no princípio constitucional do regime de colaboração.

\section{O atendimento à educação infantil nas redes estaduais}

Um primeiro dado a ser destacado na análise das matrículas totais de Educação Infantil nos estados brasileiros é que, ainda que esta etapa tenha o município como ente federado com ação prioritária para sua oferta, é possível verificar a existência de matrículas estaduais de creche e pré-escola em alguns estados, configurando uma oferta direta de matrícula pública estadual de El. Contudo, ao mesmo tempo em que se percebe a existência dessa oferta estadual, destacase, de modo geral, sua baixíssima atuação e drástica diminuição ao longo dos anos.

Ao se debruçar pelos estados distribuídos por região administrativa, verificamse algumas variâncias nas matrículas de Educação Infantil. A tabela 1 apresenta dados da região Norte:

Tabela 1: Matrículas totais na educação infantil, PIB e partidos do governador em anos selecionados - Região Norte 


\section{movimento}

faculdade de educação - programa de pós-graduação em educação

universidade federal fluminense issn 2359-3296

ano 3 número 5 - 2016

\begin{tabular}{|c|c|c|c|c|c|c|c|c|c|c|c|c|c|c|c|}
\hline \multirow[t]{2}{*}{ Norte } & \multicolumn{4}{|c|}{ Partido } & \multicolumn{3}{|c|}{ PIB/ Per Capita } & \multicolumn{4}{|c|}{$\begin{array}{l}\text { Matrícula Creche } \\
\text { Estadual }\end{array}$} & \multicolumn{4}{|c|}{$\begin{array}{c}\text { Matrícula Pré-Escola } \\
\text { Estadual }\end{array}$} \\
\hline & 2005 & 2008 & 2012 & 2015 & 2005 & 2008 & 2012 & 2005 & 2008 & 2012 & 2015 & 2005 & 2008 & 2012 & 2015 \\
\hline Acre & PT & PT & PT & PT & 11.869 & 15.609 & 16.992 & 0 & 0 & 156 & 180 & 12.907 & 4.405 & 2.426 & 373 \\
\hline Amapá & PDT & PDT & PSB & PDT & 13.025 & 17.402 & 20.287 & 190 & 0 & 0 & 21 & 8.014 & 2.015 & 307 & 246 \\
\hline Amazonas & PMDB & PMDB & PROS & PROS & 18.303 & 22.105 & 25.601 & 0 & 0 & 0 & 15 & 274 & 60 & 26 & 6 \\
\hline Pará & PSDB & PT & PSDB & PSDB & 9.962 & 12.607 & 17.451 & 778 & 337 & 121 & 137 & 1.792 & 303 & 488 & 356 \\
\hline Rondônia & PSDB & PPS & PMDB & PMDB & 14.912 & 18.891 & 24.091 & 448 & 601 & 665 & 508 & 1.638 & 994 & 703 & 712 \\
\hline Roraima & PSDB & PSDB & PSDB & PSB & 14.407 & 18.683 & 20.913 & 228 & 0 & 0 & 0 & 6.567 & 540 & 0 & 0 \\
\hline Tocantins & PMDB & PMDB & PSDB & PMDB & 12.339 & 16.125 & 18.566 & 52 & 82 & 0 & 139 & 942 & 582 & 0 & 53 \\
\hline
\end{tabular}

Fonte: as autoras com base em dados coletados nos sites do INEP (sinopse estatística), IBGE e Tribunais Regionais eleitorais

Nessa região, destacam-se Pará e Rondônia na oferta direta de matrículas em creches e pré-escolas, contudo, com uma queda significativa se comparadas no intervalo de 2005 a 2015. Acre e Amapá revelaram forte atuação na oferta de matrículas estaduais de pré-escola em 2005, as quais superavam a oferta privada naquele ano, contudo, as matrículas estaduais também diminuíram drasticamente nas gestões que se seguiram, tornando-se inferiores à oferta privada.

Ao analisar a distribuição das matrículas e os diferentes governos no período analisado, um primeiro elemento a considerar é a continuidade por uma ou mais gestões de um mesmo partido à frente do executivo. Dado ser este um aspecto a ser considerado na definição das opções de políticas, destacamos, na região Norte, que: o PSDB (Partido da Social Democracia Brasileira) manteve-se por três gestões consecutivas à frente do executivo de Roraima. Neste estado, registramos a retirada completa da oferta de vagas pelo governo do estado para o atendimento da educação infantil na creche, fechando, já em 2008, mais de 6 mil vagas estaduais de pré-escola, chegando a nenhum atendimento em 2012. 


\section{movimento}

faculdade de educação - programa de pós-graduação em educação

universidade federal fluminense issn 2359-3296

ano 3 número 5 - 2016

Em contrapartida a essa opção política, destaca-se que o PIB do referido estado nesse período teve um aumento de $45 \%$.

No Acre, também temos a permanência de um mesmo partido à frente do executivo, o Partido dos Trabalhadores (PT), e da mesma forma pode-se verificar um aumento do PIB em 43\%, de 2005 a 2012. Neste estado, a tendência de retirada da participação do sistema estadual na oferta direta de vagas na educação infantil, também de observa: entre 2005 e 2015, o sistema estadual de ensino fechou mais de 12 mil vagas de pré-escola, ainda que criado pouco mais que 300 vagas em creches.

Já em Rondônia, apesar da alternância partidária, observa-se nas últimas gestões um aumento no número de matrículas na creche ofertada pelo sistema estadual e uma tentativa de manutenção do número de matrículas da pré-escola. Nos demais estados as alterações são inerciais e atestam a baixa participação direta dos governos estaduais na oferta de vagas. Entretanto, em todos eles assiste-se ao aumento do percentual do PIB nos 10 anos analisados, bem como o aumento da oferta de creche por parte de instituições privadas.

Na região Nordeste, onde se encontra os estados mais pobres da federação, é possível verificar um baixíssimo atendimento estadual de Educação Infantil, como revela a tabela 2 .

Tabela 2: Matrículas totais na educação infantil, PIB e partidos do governador em anos selecionados - Região Nordeste

\begin{tabular}{|c|c|c|c|c|c|c|c|c|c|c|c|c|c|c|c|}
\hline \multirow[t]{2}{*}{ Nordeste } & \multicolumn{4}{|c|}{ Partido } & \multicolumn{3}{|c|}{ PIB/ Per Capita } & \multicolumn{4}{|c|}{$\begin{array}{l}\text { Matrícula Creche } \\
\text { Estadual }\end{array}$} & \multicolumn{4}{|c|}{$\begin{array}{c}\text { Matrícula Pré-Escola } \\
\text { Estadual }\end{array}$} \\
\hline & 2005 & 2008 & 2012 & 2015 & 2005 & 2008 & 2012 & 2005 & 2008 & 2012 & 2015 & 2005 & 2008 & 2012 & 2015 \\
\hline Alagoas & PSB & PSDB & PSDB & PMDB & 8.313 & 9.823 & 13.928 & 0 & 0 & 0 & 3 & 1.150 & 946 & 322 & 320 \\
\hline Bahia & PFL & PT & PT & PT & 11.676 & 13.215 & 16.370 & 3.998 & 658 & 150 & 55 & 4.046 & 980 & 774 & 833 \\
\hline
\end{tabular}




\section{$\operatorname{movim}_{\text {revistade equcaço }}$}

faculdade de educação - programa de pós-graduação em educação

universidade federal fluminense issn 2359-3296

ano 3 número 5 - 2016

\begin{tabular}{lcccccccccccccccc} 
Ceará & PSDB & PSB & PSB & PT & 8.964 & 11.218 & 14.322 & 146 & 284 & 176 & 246 & 1.179 & 1.088 & 958 & 809 \\
\hline Maranhão & PFL & PDT & PMDB & PCdoB & 7.360 & 9.627 & 11.465 & 0 & 0 & 0 & 7 & 4.172 & 731 & 183 & 144 \\
\hline Paraíba & PSDB & PSDB & PSB & PSB & 8.318 & 10.830 & 14.173 & 1.917 & 1.913 & 1.679 & 23 & 18.456 & 3.759 & 1.333 & 119 \\
\hline Pernambuco & PMDB & PSB & PSB & PSB & 10.519 & 12.721 & 18.216 & 295 & 264 & 327 & 368 & 4.741 & 3.719 & 1.832 & 1.863 \\
\hline Piauí & PT & PT & PSB & PT & 6.562 & 8.474 & 11.530 & 66 & 23 & 66 & 0 & 2.866 & 993 & 5 & 0 & 0 \\
\hline $\begin{array}{l}\text { Rio Grande } \\
\text { do Norte }\end{array}$ & PSB & PSB & DEM & PSDB & 10.549 & 12.938 & 18.292 & 147 & 72 & 0 & 0 & 1.559 & 479 & 0 & 0 \\
\hline Sergipe & PFL & PT & PT & PMDB & 12.098 & 15.425 & 19.780 & 66 & 106 & 0 & 0 & 9.676 & 2.974 & 0 & 0 &
\end{tabular}

Fonte: as autoras com base em dados coletados nos sites do INEP (sinopse estatística), IBGE e Tribunais Regionais eleitorais

Em relação à matrícula estadual, destacam-se os estados da Bahia e Paraíba que, em 2005, tinham considerável número de matrículas em creches, se comparados aos demais estados da região, sendo que em 2015 este número torna-se ínfimo. Na Paraíba a queda da matrícula estadual em creche torna-se brusca na última gestão, mesmo permanecendo o mesmo partido (Partido Socialista Brasileiro - PSB) na gestão. Nesse estado também se verifica um número significativo de 18.456 matrículas de pré-escola na rede estadual, em 2005 , sendo que este número diminui para 3.759 , em 2010, cai para 1.333, em 2012, chegando a apenas 119 matrículas, em 2015, período no qual o PIB do estado aumentou $70 \%$.

$\mathrm{Na}$ oferta de matrícula estadual para creche, Pernambuco apresenta-se como o estado em que, apesar de troca de partido na gestão de 2007 a 2010, a oferta permaneceu estável; por outro lado, as matrículas da pré-escola tiveram queda significativa. Ainda que com números diferentes, Ceará também apresenta tendência semelhante, com um pequeno aumento do número de matrículas em creches.

No que se refere às legendas de filiação dos governadores em exercício, identifica-se que o PT, o PSDB e o PSB são os partidos que mais tempo 


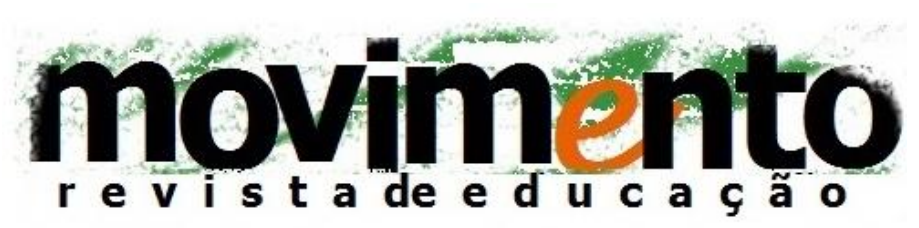

faculdade de educação - programa de pós-graduação em educação

universidade federal fluminense issn 2359-3296

ano 3 número 5 - 2016

permaneceram à frente dos executivos desses estados. Não se percebe medidas específicas para opção de atendimento relacionada às legendas. Todos os casos apresentam aumento de matrículas na esfera privada e diminuição da presença do sistema estadual nesse atendimento, em alguns casos, dramaticamente como já observado na Paraíba, durante as gestões do PSB.

A tabela 3 apresenta, como nas tabelas anteriores, informações para que se explore e indague a respeito das tendências observadas na região Centro-Oeste. Nela, verifica-se movimento semelhante às regiões anteriormente analisadas, de queda da matrícula estadual para oferta da El.

Goiás destaca-se pela não oferta de creche estatal no período analisado e uma queda significativa da oferta de pré-escola, com a tendência de que nos próximos anos esse número chegue a zerar, assim como o atendimento em creche. Nesse Estado, verifica-se também um número expressivo da matrícula privada na préescola (43.521, em 2015), tendo esta tido um aumento nos governos do PSDB e do PP (Partido Progressista), além de um crescimento considerável de $80 \%$ do PIB no período de 2005 a 2012.

Na região Centro-Oeste destaca-se ainda o estado de Mato Grosso do Sul pelo maior aumento do PIB no período de 2005 a 2012, se comparado aos demais estados brasileiros (superando o crescimento de Goiás): $86 \%$. Contudo, verificase que também nesse estado o aumento do PIB, ainda que expressivo, não influenciou positivamente na oferta de vagas na Educação Infantil, tendo as gestões do PMDB (Partido do Movimento Democrático Brasileiro) atuado na diminuição de matrículas estaduais em creches e pré-escolas.

Tabela 3: Matrículas totais na educação infantil, PIB e partidos do governador em anos selecionados - Região Centro-Oeste 


\section{movimento}

faculdade de educação - programa de pós-graduação em educação

universidade federal fluminense issn 2359-3296

ano 3 número 5 - 2016

\begin{tabular}{|c|c|c|c|c|c|c|c|c|c|c|c|c|c|c|c|}
\hline \multirow{2}{*}{$\begin{array}{l}\text { Centro- } \\
\text { Oeste }\end{array}$} & \multicolumn{4}{|c|}{ Partido } & \multicolumn{3}{|c|}{ PIB/ Per Capita } & \multicolumn{4}{|c|}{$\begin{array}{l}\text { Matrícula Creche } \\
\text { Estadual }\end{array}$} & \multicolumn{4}{|c|}{$\begin{array}{c}\text { Matrícula Pré-Escola } \\
\text { Estadual }\end{array}$} \\
\hline & 2005 & 2008 & 2012 & 2015 & 2005 & 2008 & 2012 & 2005 & 2008 & 2012 & 2015 & 2005 & 2008 & 2012 & 2015 \\
\hline Goiás & PSDB & PP & PSDB & PSDB & 15.948 & 20.314 & 28.656 & 20 & 0 & 0 & 0 & 926 & 731 & 183 & 97 \\
\hline $\begin{array}{l}\text { Mato } \\
\text { Grosso }\end{array}$ & PPS & PPS & PMDB & PSDB & 23.704 & 28.277 & 32.528 & 463 & 420 & 158 & 191 & 1.113 & 390 & 303 & 432 \\
\hline $\begin{array}{l}\text { Mato } \\
\text { Grosso do } \\
\text { Sul }\end{array}$ & PT & PMDB & PMDB & PSDB & 16.950 & 22.380 & 31.494 & 1.471 & 183 & 212 & 291 & 2.350 & 153 & 118 & 163 \\
\hline
\end{tabular}

Na região Sudeste, verifica-se a presença de apenas três partidos alternando-se na gestão dos estados: PSDB; PSB e PMDB. Com exceção do Espírito Santo, estado no qual durante o período não se encontram matrículas estaduais na Educação Infantil, tem-se, nos demais estados, a forte diminuição das matrículas estaduais em creches e pré-escolas do primeiro para o segundo mandato governamental. Tendência mantida pela gestão subsequente, independente dos partidos.

Em São Paulo, verifica-se que, enquanto a matrícula estadual de creche teve uma queda de 83\%, a matrícula privada cresceu 155\%, de 2005 a 2015. Queda ainda maior pode ser observada nas matrículas da pré-escola estadual: $88 \%$. Esse estado contou com um único partido nas últimas gestões do período analisado, o PSDB, e teve um aumento de 48\% do PIB de 2005 a 2012.

Em Minas Gerais, estado em que também houve três mandatos consecutivos do PSDB, verifica-se a diminuição, em dez anos, da oferta estadual de pré-escola em cerca de $97 \%$, sendo a oferta de creche quase nula. No caso do Rio de Janeiro, no período entre o governo do PSB para o segundo ano do primeiro mandato do PMDB, a diminuição da matrícula estadual da pré-escola foi da ordem de $80,3 \%$, tendência mantida até 2015 , ano no qual a redução atingiu $97,8 \%$, na atuação consecutiva de dois governos PMDB; o atendimento de 


\section{movimento}

faculdade de educação - programa de pós-graduação em educação

universidade federal fluminense issn 2359-3296

ano 3 número 5 - 2016

creche estadual diminuiu em $83 \%$ nesse estado, no período analisado. Semelhantemente aos demais estados da região, MG e RJ tiveram um aumento do PIB no período de dez anos, na ordem de 59\% e 58\%, respectivamente.

Tabela 4: Matrículas totais na educação infantil, PIB e partidos do governador em anos selecionados - Região Sudeste

\begin{tabular}{|c|c|c|c|c|c|c|c|c|c|c|c|c|c|c|c|}
\hline \multirow[t]{2}{*}{ Sudeste } & \multicolumn{4}{|c|}{ Partido } & \multicolumn{3}{|c|}{ PIB/ Per Capita } & \multicolumn{4}{|c|}{$\begin{array}{l}\text { Matrícula Creche } \\
\text { Estadual }\end{array}$} & \multicolumn{4}{|c|}{$\begin{array}{c}\text { Matrícula Pré-Escola } \\
\text { Estadual }\end{array}$} \\
\hline & 2005 & 2008 & 2012 & 2015 & 2005 & 2008 & 2012 & 2005 & 2008 & 2012 & 2015 & 2005 & 2008 & 2012 & 2015 \\
\hline $\begin{array}{l}\text { Espírito } \\
\text { Santo }\end{array}$ & PSB & PMDB & PSB & PMDB & 24.557 & 31.911 & 41.532 & 0 & 0 & 0 & 0 & 0 & 0 & 0 & 0 \\
\hline $\begin{array}{l}\text { Minas } \\
\text { Gerais }\end{array}$ & PSDB & PSDB & PSDB & PT & 17.757 & 22.450 & 28.318 & 28 & 161 & 0 & 23 & 14.007 & 7.618 & 153 & 472 \\
\hline $\begin{array}{l}\text { Rio de } \\
\text { Janeiro }\end{array}$ & PSB & PMDB & PMDB & PMDB & 28.470 & 34.104 & 45.009 & 538 & 477 & 81 & 94 & 16.265 & 3.206 & 529 & 351 \\
\hline São Paulo & PSDB & PSDB & PSDB & PSDB & 31.884 & 38.576 & 47.237 & 4.043 & 744 & 789 & 689 & 3.292 & 558 & 406 & 379 \\
\hline
\end{tabular}

A última região administrativa considerada, região Sul, cujos dados integram a tabela 5 , esteve no período selecionado, submetida à gestão prioritariamente do PMDB e do PSDB. Aqui se destaca a ação marcante de transferência, tanto no Rio Grande do Sul (RS), quanto em Santa Catarina (SC), do atendimento na préescola para outras esferas administrativas. No Paraná, o atendimento à educação infantil por parte do governo estadual foi sempre residual.

No Rio Grande do Sul temos uma diminuição no atendimento estadual na préescola, da ordem de $85 \%$ em todo o período analisado; destaca-se nesse estado o aumento da matrícula privada da El, sobretudo na creche que, em dez anos, atingiu $148 \%$ de crescimento. Já em Santa Catarina, os governos estaduais diminuem em $99,6 \%$ sua presença na oferta direta da pré-escola. No caso das creches, a partir de 2008, a oferta pelo sistema estadual diminui drasticamente e passa a ser residual. Tanto RS como SC tiveram um aumento do PIB, $44 \% \mathrm{e}$ 48\%, respectivamente, entre 2005 e 2015. 


\section{movimento}

faculdade de educação - programa de pós-graduação em educação

universidade federal fluminense

issn 2359-3296

ano 3 número 5 - 2016

No Paraná destaca-se a ausência de matrícula direta da rede estadual para creche (enquanto a matrícula privada aumentou na ordem de $46 \%$, no período analisado) e também chama a atenção a baixa oferta estadual de matrículas da pré-escola, se comparado com os demais estados da região, apresentando ainda uma diminuição de $63 \%$ deste atendimento nos dez selecionados. 0 Paraná também se revela como o estado da região Sul que apresentou maior crescimento do PIB, 57\%, entre 2005 e 2012, como pode ser verificado na tabela 5.

Tabela 5: Matrículas totais na educação infantil e partidos do governador em anos selecionados - Região Sul

\begin{tabular}{|c|c|c|c|c|c|c|c|c|c|c|c|c|c|c|c|}
\hline \multirow[t]{2}{*}{ Sul } & \multicolumn{4}{|c|}{ Partido } & \multicolumn{3}{|c|}{ PIB/ Per Capita } & \multicolumn{4}{|c|}{$\begin{array}{l}\text { Matrícula Creche } \\
\text { Estadual }\end{array}$} & \multicolumn{4}{|c|}{$\begin{array}{c}\text { Matrícula Pré-Escola } \\
\text { Estadual }\end{array}$} \\
\hline & 2005 & 2008 & 2012 & 2015 & 2005 & 2008 & 2012 & 2005 & 2008 & 2012 & 2015 & 2005 & 2008 & 2012 & 2015 \\
\hline Paraná & PMDB & PMDB & PSDB & PSDB & 21.884 & 26.701 & 34.325 & 93 & 0 & 1 & 62 & 1.553 & 690 & 459 & 578 \\
\hline $\begin{array}{l}\text { Santa } \\
\text { Catarina }\end{array}$ & PMDB & PMDB & PSD & PSD & 25.786 & 32.128 & 38.219 & 1.498 & 63 & 61 & 67 & 20.553 & 11.594 & 73 & 39 \\
\hline $\begin{array}{l}\text { Rio } \\
\text { Grande do } \\
\text { Sul }\end{array}$ & PMDB & PSDB & PT & PMDB & 23.607 & 28.988 & 33.930 & 170 & 212 & 218 & 199 & 56.910 & 21.683 & 9.606 & 8.431 \\
\hline
\end{tabular}

Fonte: as autoras com base em dados coletados nos sites do INEP (sinopse estatística), IBGE e Tribunais Regionais eleitorais

\section{Considerações finais}

Neste estudo, de caráter exploratório, buscou-se analisar informações sobre o conjunto dos estados brasileiros para a oferta estadual da Educação Infantil, mediante dados de matrícula estadual, dados do PIBs de cada estado e dos partidos dos governadores no período de 2005 a 2015, de modo a questionar a participação ou ausência do governo estadual na garantia do direito à El, o qual, 


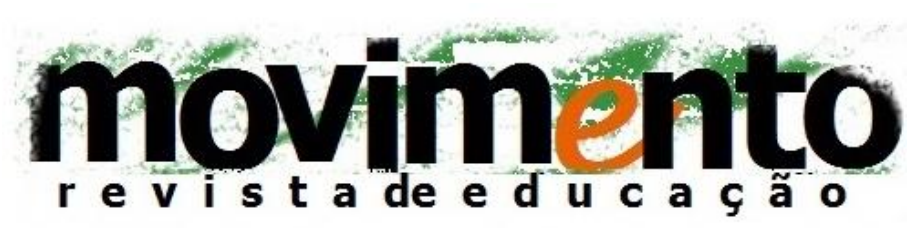

faculdade de educação - programa de pós-graduação em educação

universidade federal fluminense issn 2359-3296

ano 3 número 5 - 2016

apesar de ser responsabilidade prioritária do município, deve se efetivar em um regime de colaboração entre os entes federados.

Tal tema merece destaque se se pensar que, desde a EC/59, debate-se a necessidade de regulamentação das formas de cooperação interfederativas, temática reforçada com a vigência do atual PNE. Não raras as manifestações em contrário partem exatamente dos gestores estaduais. Na compreensão de Abicalil (2014, p. 253), embora a educação infantil "constitua uma competência prioritária dos municípios, é notória a responsabilidade comum para a garantia do acesso ao serviço educacional, como antevê o artigo 23 da Constituição Federal".

Dessa maneira, este trabalho ressalta a necessidade de revisão do pacto federativo no âmbito de formas de cooperação para a oferta da educação no país. No que diz respeito à El, as perspectivas continuam preocupantes dado que os municípios terão que adequar seus sistemas à obrigatoriedade de atendimento a todas as crianças a partir do 4 anos de idade e responder à necessidade de expansão da oferta de creche e pré-escola e do cumprimento das metas e estratégias do Plano Nacional de Educação.

Dado que a El é considerada uma das etapas que demanda maior investimento, pelas especificidades de seu atendimento (BASSI, 2011; ARELARO, 2008), mais recursos serão necessários diante dos intentos anteriormente apresentados e especialmente diante da possível regulamentação do Custo Aluno Qualidade Inicial (Caqi), situação que exigirá a cooperação dos governos estaduais aos municípios, especialmente nas regiões mais pobres do país: Norte e Nordeste. 


\section{movimento \\ faculdade de educação - programa de pós-graduação em educação \\ universidade federal fluminense issn 2359-3296 \\ ano 3 número 5 - 2016}

Dentro desse contexto, os dados aqui apresentados indagam sobre possíveis correlações que demandam estudos mais aprofundados: a saída do governo do estado da oferta direta de matrícula na El, nos últimos anos, tem contribuído para o aumento alarmante da iniciativa privada na oferta de creche e pré-escola? Essa ausência de cooperação do governo do estado na oferta direta das matrículas de El, tem onerado os municípios, contribuindo para que estes optem por convênios com o setor privado para atendimento dessa etapa da educação, como apontam as pesquisas (ADRIÃO et al, 2009; Arelaro et al. 2011)

Incorporando as indagações decorrentes desse estudo, encontra-se a necessidade de análise da diminuição da presença da oferta direta da El pelos governos estaduais a partir de 2006: seria esta uma consequência do impacto do FUNDEB ou da LRF, ou mesmo de uma associação dos dois fatores?

Em uma análise geral, pôde-se verificar que, independentemente de partido do governador no período analisado, há um forte movimento de diminuição das matrículas da EI na rede estadual. Outro dado nacional é o crescimento do PIB dos estados no período analisado e sua não correspondência com a oferta direta da El, o que nos indica uma opção política dos governadores de atuação em outras áreas e/ou etapas da educação que não a creche e pré-escola.

Em alguns estados a oferta direta de creche e pré-escola na rede estadual pode estar associada às creches universitárias, como ocorre, por exemplo, na região Sudeste. Contudo, convém ressaltar que mesmo nesses estados a matrícula de El apresenta queda contínua, o que pode significar, em alguns casos, também a diminuição do atendimento nas creches universitárias, como vem ocorrendo com as creches da Universidade de São Paulo que, desde 2015, vem fechando vagas 


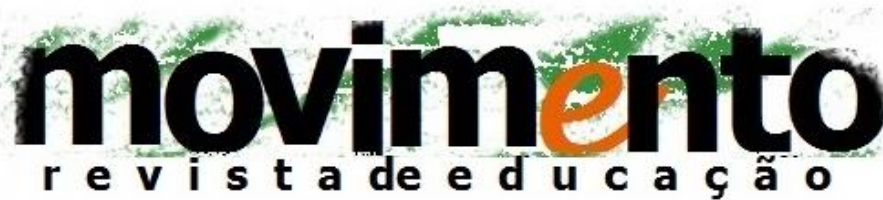

faculdade de educação - programa de pós-graduação em educação

universidade federal fluminense issn 2359-3296

ano 3 número 5 - 2016

e gerando indignação de pais e funcionários que passaram a se mobilizar contra o encerramento do atendimento à El naquela instituição.

Considerando que em 2014, $11 \%$ das crianças de 4 e 5 anos ainda não eram atendidas na pré-escola e que a extensão da obrigatoriedade escolar exigiria 0 ingresso de aproximadamente mais de 600 mil crianças na pré-escola; considerando ainda que até 2024 mais 2,4 milhões de crianças de 0 a 3 anos deverão ser atendidas em creches, não é difícil imaginar os esforços que os governos locais precisarão fazer para atender ao contido na Lei. A esse cenário, de ampliação da demanda, somam-se novas exigências aos governos estaduais, os quais devem atender até 2016, mais 2 milhões de adolescentes de 15 a 17 anos no Ensino Médio8.

A situação objetiva na qual funcionam as escolas públicas poderá ser agravada com a recente aprovação da desoneração das receitas de impostos da União, seguida da provável desoneração de impostos de estados e de municípios, com implicações certamente mais funestas para a efetivação do direito à educação infantil, quando da ausência de formas cooperativas para sua realização. Tal contexto agrava-se ainda mais com a recente aprovação da chamada "PEC do ajuste fiscal", pela qual se congela por 20 anos a ampliação do investimento público em educação, na medida em que o atrela ao índice inflacionário do ano anterior, colocando em risco o direito à educação das crianças e jovens brasileiros.

\footnotetext{
${ }^{8}$ Não estamos considerando nesta breve reflexão as demandas decorrentes da mesma lei pela ampliação da jornada escolar para 25\% dos alunos da educação básica até 2024 .
} 


\section{movimento \\ faculdade de educação - programa de pós-graduação em educação \\ universidade federal fluminense issn 2359-3296 \\ ano 3 número 5 - 2016}

\section{Referências Bibliográficas}

ABICALIL. C. O federalismo e o Sistema Nacional de Educação: uma oportunidade fecunda. Revista Retratos da Escola, Brasília, v. 8, n. 15, p. 249263, jul./dez. 2014.

ADRIÃO, T.; GARCIA, T.; BORGHI, R. F.; ARELARO, L. R. G. . Uma modalidade peculiar de privatização da educação pública: a aquisição de 'sistemas de ensino' por municípios paulistas. Educação \& Sociedade, Campinas, v. 30, p. 799-818, 2009

ADRIÃO, T. e BEZERRA, E. O setor não lucrativo na gestão da educação pública: corresponsabilidade ou debilidade. Currículo sem Fronteiras, v. 13, n. 2, p. 256-268, maio/ago. 2013.

ADRIÃO, T. Relações entre o público e o privado na oferta educacional no Brasil In: Pinto et al. Para onde vai o dinheiro?.1 ed. São Paulo : Xamã, 2014, p. 97112.

ADRIÃO, T. Dimensões da privatização da educação básica no Brasil a partir de 1990: um diálogo com a produção acadêmica. Tese de Livre Docência em Educação. Unicamp, 2015. 227p.

ADRIAO, T. et al . As parcerias entre prefeituras paulistas e o setor privado na política educacional: expressão de simbiose?. Educação \& Sociedade, Campinas, v. 33, n. 119, p. 533-549, Junho, 2012.

ARAÚJO, Gilda Cardoso de. Políticas educacionais e Estado federativo: conceitos e debates sobre a relação entre município, federação e educação no Brasil. Curitiba: Appris, 2013.

ARELARO, L. R. G. A não-transparência nas relações público-privadas: o caso das creches conveniadas. In: Theresa Adrião; Vera Peroni. (Org.). Público e Privado na Educação: novos elementos para o debate. São Paulo: Xamã, 2008, v. 1 , p. $51-66$ 


\section{movimento \\ faculdade de educação - programa de pós-graduação em educação \\ universidade federal fluminense issn 2359-3296 \\ ano 3 número 5 - 2016}

ARELARO, L. R. G ; Jacomini, M.A. ; KLEIN, S. B. . O ensino fundamental de nove anos e o direito à educação. Educação e Pesquisa (USP), São Paulo, v. 37 , p. 35-51, 2011

BASSI, M. E. Financiamento da educação infantil em seis capitais Brasileiras. In: Cadernos de Pesquisa, São Paulo: Jan./Apr. 2011, vol.41 no.142.

BRASIL. Constituição (1988). Constituição da República Federativa do Brasil. Brasília, DF: Senado Federal: 1988.

BRASIL. Lei n. 13.005, de 25 de junho de 2014. Aprova o Plano Nacional de Educação e dá outras providências.

BRASIL. Lei no 9.394/96, de 20 de dezembro de 1996. Estabelece as diretrizes e bases da educação nacional. Diário Oficial da União: República Federativa do Brasil, Brasília, DF, 23 de dezembro de 1996.

HILL, D. O neoliberalismo global, a resistência e a deformação da educação. Currículo sem Fronteiras, v.3, n.2, pp.24-59, Jul/Dez 2003

MENEZES, R. \& TONETO Jr., R.. Regras fiscais no Brasil: a influência da LRF sobre as categorias de despesa dos municípios, In: Planejamento e Políticas Públicas (29), p. 7-37, 2006.

OLIVEIRA, C.; GANZELI, P.. Relações Intergovernamentais na educação: fundos, convênios, consórcios públicos e arranjos de desenvolvimento da educação. Educação \& Sociedade, Campinas, v. 34, p. 1031-1048, 2013.

PERONI, Vera Maria Vidal. Política educacional e papel do Estado no Brasil dos anos 90. São Paulo: Xamã, 2003.

PINTO, José Marcelino de Rezende. A política recente de fundos para o financiamento da educação e seus efeitos no pacto federativo. Educação \& Sociedade. Campinas, v. 28, n. 100, p. 877-897, 2007.

PINTO, J. M. R.; ALVES, T.. O impacto financeiro da ampliação da obrigatoriedade escolar no contexto do FUNDEB. Educação e Realidade, v. 36, p. 605-624, 2011. 